\title{
Performa Fungi Mikoriza Arbuskula dan Pueraria phaseoloides yang Dipupuk Tepung Tulang dengan Ukuran dan Dosis Berbeda
}

\author{
Performance of Arbuscular Mycorrhizal Fungi and Pueraria phaseoloides Fertilized by Bone Meal \\ Differing in Size and Dosage
}

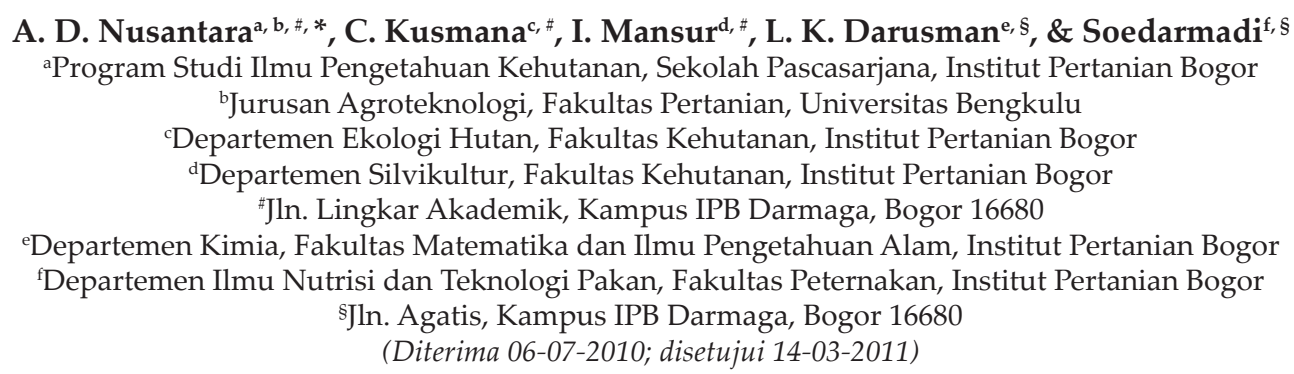

\begin{abstract}
ABSTRAK
Tepung tulang merupakan bahan alami yang dapat digunakan sebagai sumber fosfor (P) dan kalsium (Ca) yang diperlukan untuk pertumbuhan tanaman. Unsur P dapat menimbulkan masalah, karena dapat menghambat pembentukan dan perkembangan fungi mikoriza arbuskula (FMA) jika diberikan dengan takaran yang tinggi. Penelitian ini bertujuan mendapatkan ukuran garis tengah dan takaran tepung tulang terbaik untuk memproduksi inokulan FMA Glomus etunicatum NPI-126 dan biomassa tanaman Pueraria phaseoloides Roxb. Percobaan rumah kaca dilaksanakan dengan rancangan kelompok yang terdiri atas 13 perlakuan (kontrol dan 12 kombinasi berbagai ukuran garis tengah dan takaran tepung tulang sapi) dan tiga kelompok. Tepung tulang dan pupuk buatan menghasilkan pengaruh berbeda tidak nyata $(P>0,05)$ dalam meningkatkan bobot kering tanaman $P$. phaseoloides. Penggunaan tepung tulang berukuran garis tengah $<250 \mu \mathrm{m}$ yang diberikan dengan takaran 25-40 mg per pot nyata $(\mathrm{P}<0,05)$ meningkatkan bobot kering tanaman $P$. phaseoloides. Penggunaan tepung tulang nyata $(P<0,05)$ menurunkan kolonisasi akar namun menghasilkan jumlah spora $G$. etunicatum NPI-126 yang nyata $(\mathrm{P}<0,05)$ lebih tinggi dibandingkan pupuk buatan. Ukuran garis tengah tepung tulang yang semakin kecil nyata meningkatkan kolonisasi dan jumlah spora $G$. etunicatum NPI-126.
\end{abstract}

Kata kunci: G. etunicatum, P. phaseoloides, tepung tulang, produksi inokulum

\section{ABSTRACT}

Bone meal is a natural source of calcium and phosphorus required for plant growth, but phosphorus can cause problems if they occur in high concentrations particularly will inhibit growth of mycorrhizal fungi. The aim of this study was to find the best diameter size and dosage of bone meal for increasing growth of forage legume Pueraria phaseoloides and for producing arbuscular mycorrhizal fungi (AMF) Glomus etunicatum inoculant. A glass house experiment was laid out in a randomized block design consisted of 13 treatments (control and 12 combination of different diameter size and weight of bone meal) and replicated three times. Bone meal and artificial fertilizer resulted the same effect $(P>0.05)$ on dry matter of $P$. phaseoloides. Application of $25-40 \mathrm{mg}$ with $<250$ $\mu \mathrm{m}$ diameter significantly $(\mathrm{P}<0.05)$ increased dry matter production. Bone meal reduced significantly $(\mathrm{P}<0.05)$ root colonization but increased significantly number of spores compared to that of artificial fertilizer. Reducing bone meal diameter significantly increased root colonization and number of spores of AMF G. etunicatum.

Key words: G. etunicatum, P. phaseoloides, bone meal, inoculum production

\footnotetext{
* Korespondensi:

Telp. 0736 341388, e-mail: abimanyu.dn@gmail.com
} 


\section{PENDAHULUAN}

Peran fungi mikoriza arbuskula (FMA) untuk meningkatkan pertumbuhan, hasil, dan mutu tanaman pakan ternak telah diketahui dengan baik (Karti, 2004; Lukiwati, 2007). Propagul (spora, miselium, dan akar terkolonisasi) merupakan struktur untuk mempertahankan kelestarian FMA di alam, namun demikian propagul dapat hilang karena bencana alam dan aktivitas antropogen. Produksi inokulum atau propagul FMA dengan demikian berperan penting karena selain dapat menghasilkan inokulan komersial untuk meningkatkan pertumbuhan tanaman, juga dapat menyelamatkan dan melestarikan plasma nutfah FMA dari kemusnahan.

Glomus etunicatum (Becker \& Gerdemann) merupakan salah satu FMA yang dijumpai pada berbagai ekosistem. Sporulasi atau pembentukan sporanya berkorelasi positif dengan kadar hara $\mathrm{P}$ (Carrenho et al., 2001) dan meningkat pesat jika ditumbuhkan dalam pot (Troeh \& Loynachan, 2009). G. etunicatum mampu memfasilitasi tanaman legum untuk bersimbiosis dengan rhizobia (Siviero et al., 2008), memperkaya tanah rhizosfir kaya dengan karbon, bakteri dan fungi sehingga memiliki aktivitas biologis yang lebih tinggi (Smith \& Read, 2008).

Produksi inokulum FMA pada umumnya dilakukan pada kultur pot terbuka menggunakan satu atau lebih isolat FMA, tanaman inang tertentu (sorghum, puero, jagung dan sebagainya), bahan mineral alami (pasir, zeolit) sebagai medium tumbuh, dan pupuk buatan sebagai sumber hara (Feldmann et al., 2009). Salah satu sumber hara yang berpotensi untuk digunakan dalam produksi inokulan FMA ialah tepung tulang mengingat harganya yang murah, mudah didapat, dan ramah lingkungan.

Tepung tulang semenjak akhir abad ke delapan belas telah dipandang sebagai pupuk penyedia unsur hara P. Namun demikian, semenjak tahun 1950 -an peran tepung tulang sebagai pupuk telah digantikan oleh pupuk buatan yang mengandung hara $\mathrm{P}$ lebih tinggi, sebagai akibatnya minat petani dan peneliti untuk memanfaatkan dan meneliti tepung tulang termasuk potensinya sebagai sumber hara P dalam produksi inokulum FMA juga berkurang drastis (Romer, 2006). Tepung tulang mampu melepaskan $\mathrm{P}$ secara lambat yang sebanding dengan batuan fosfat, atau pada beberapa jenis tanah memiliki efektivitas yang sama dengan pupuk superfosfat. Kombinasi inokulasi G. etunicatum dan pemberian tepung tulang sapi telah dilaporkan mampu menghasilkan pertumbuhan tanaman pakan ternak Pueraria phaseoloides var. Javanica yang sama baiknya dengan yang diberi pupuk buatan (Nusantara et al., 2007).

Namun demikian sejauh ini belum ditentukan ukuran diameter dan dosis yang tepat khususnya untuk kepentingan meningkatkan biomassa pakan ternak $P$. phaseoloides dan memproduksi inokulum FMA G. etunicatum. Oleh sebab itu penelitian ini dirancang dengan tujuan untuk menentukan ukuran diameter dan dosis optimal tepung tulang untuk meningkatkan biomassa tanaman $P$. phaseoloides dan memproduksi inokulum FMA G. etunicatum dibandingkan larutan pupuk buatan.

\section{MATERI DAN METODE}

\section{Prosedur Percobaan}

Spora G. etunicatum NPI-126 diperoleh dari Laboratorium Bioteknologi Hutan dan Lingkungan, Pusat Penelitian Sumberdaya Hayati dan Bioteknologi, Institut Pertanian Bogor, dan diperbanyak dengan metode kultur tunggal menggunakan $P$. phaseoloides var. Javanica sebagai tanaman inang dengan zeolit sebagai substrat, dan larutan pupuk buatan sebagai sumber hara. Ciri morfologi G. etunicatum yang digunakan pada penelitian ini adalah tidak memiliki dudukan spora, spora tunggal dan tidak menggerombol, dan hanya memiliki satu tangkai spora. Bentuk spora bulat dengan ukuran diameter $140 \mu \mathrm{m}$, berwarna kuning sampai kuning cokelat. Jumlah dinding sporanya ada dua. Dinding terluar permukaannya agak kasar, berwarna hialin, tebal 4 $\mu \mathrm{m}$. Dinding terdalam berwarna kuning cokelat dengan ketebalan $6 \mu \mathrm{m}$. Hifanya lurus dan panjang dengan percabangan bertipe huruf $\mathrm{H}$, menyebar di dalam kortek akar, intensif menyerap warna tryphan blue, dan vesikel berbentuk lonjong.

Tepung tulang sapi giling diperoleh dari Laboratorium Pengolahan Hasil Ternak Fakultas Peternakan, Institut Pertanian Bogor. Tepung tulang tersebut mengandung 1,65\% N; 12,16\% P; 0,16\% K; 19,82\% Ca; 11 $\mathrm{mg} \mathrm{kg}^{-1} \mathrm{Fe}$; $23 \mathrm{mg} \mathrm{kg}^{-1} \mathrm{Mn}$; dan $125 \mathrm{mg} \mathrm{kg}^{-1} \mathrm{Zn}$. Pupuk buatan dibeli dari toko pertanian di Darmaga, Bogor. Pupuk ini mengandung 25\% N; 1,09\% P; dan 6,08\% K.

Percobaan dilaksanakan di rumah kaca Laboratorium Silvikultur Fakultas Kehutanan Institut Pertanian Bogor. Karakterisasi morfologi spora dilakukan di Pusat Penelitian Biologi LIPI, Cibinong. Penanaman bibit $P$. phaseoloides dilaksanakan pada pot dari wadah air mineral berukuran $240 \mathrm{ml}$ berisi $175 \mathrm{~g}$ zeolit sebagai medium tumbuh dan tepung tulang sesuai perlakuan. Bibit $P$. phaseoloides berukuran seragam diletakkan pada lubang tanaman, kemudian diinokulasikan 20 buah spora FMA G. etunicatum. Perlakuan kontrol diberi larutan pupuk buatan dengan dosis $0,5 \mathrm{~g} \mathrm{l}^{-1}$ dan pemberiannya diulang setiap tiga hari sampai percobaan selesai. Bibit dipelihara selama 12 minggu dan selama percobaan kondisi air dipertahankan tetap lembab dengan cara penyiraman air setiap hari.

Satu pot diambil secara acak dari setiap ulangan kombinasi perlakuan pada umur 6 minggu setelah tanam (MST). Akar dipisahkan dari bagian atas tanaman untuk diamati kolonisasi mikorizanya dengan menggunakan larutan pewarna berupa campuran laktogliserin (campuran gliserin teknis, asam laktat teknis, dan air destilata dengan nisbah $2: 2: 1$ ) dan larutan tryphan blue 0,05\% (Biofertilizer Project Group, 2006). Kolonisasi mikoriza dihitung berdasarkan proporsi jumlah hifa, vesikel dan arbuskula dengan jumlah bidang pandang yang diamati (Biofertilizer Project Group, 2006).

Percobaan dihentikan pada umur 12 MST dan secara acak diambil satu pot plastik untuk dibongkar. Bagian atas tanaman beserta akarnya dibawa ke laboratorium untuk diukur bobot kering dan kolonisasi mikorizanya. Bobot kering diukur pasca pengeringan dalam oven bersuhu $80^{\circ} \mathrm{C}$ setelah tiga kali penimbangan, 
yaitu ketika telah tercapai bobot yang konstan. Tanaman pada pot plastik lainnya dibiarkan mengering untuk kemudian diekstrak sporanya menggunakan metode dekantasi basah yang diikuti dengan sentrifugasi dalam larutan sukrosa $60 \%$. Spora dituangkan pada cawan petri dan jumlahnya dihitung dengan bantuan mikroskop.

\section{Rancangan Percobaan dan Analisis Data}

Percobaan dilaksanakan dengan rancangan acak kelompok dengan 13 perlakuan dan tiga kelompok. Tiga belas perlakuan yang diuji adalah:

$\mathrm{T}_{1}=$ larutan pupuk buatan sebanyak $11 \mathrm{ml}$ per tiga hari (kontrol);

$\mathrm{T}_{2}=$ tepung tulang berdiameter $<250 \mu \mathrm{m}$ dosis $10 \mathrm{mg}$;

$\mathrm{T}_{3}=$ tepung tulang berdiameter $<250 \mu \mathrm{m}$ dosis $25 \mathrm{mg}$;

$\mathrm{T}_{4}=$ tepung tulang berdiameter $<250 \mu \mathrm{m}$ dosis $40 \mathrm{mg}$;

$\mathrm{T}_{5}=$ tepung tulang berdiameter $<250 \mu \mathrm{m}$ dosis $55 \mathrm{mg}$;

$\mathrm{T}_{6}^{5}=$ tepung tulang berdiameter $250-500 \mu \mathrm{m}$ dosis $10 \mathrm{mg}$;

$\mathrm{T}_{7}=$ tepung tulang berdiameter $25-500 \mu \mathrm{m}$ dosis $25 \mathrm{mg}$;

$\mathrm{T}_{8}=$ tepung tulang berdiameter $250-500 \mu \mathrm{m}$ dosis $40 \mathrm{mg}$;

$\mathrm{T}_{9}=$ tepung tulang berdiameter $250-500 \mu \mathrm{m}$ dosis $55 \mathrm{mg}$;

$\mathrm{T}_{10}=$ tepung tulang berdiameter $>500 \mu \mathrm{m}$ dosis $10 \mathrm{mg}$;

$\mathrm{T}_{11}=$ tepung tulang berdiameter $>500 \mu \mathrm{m}$ dosis $25 \mathrm{mg}$;

$\mathrm{T}_{12}=$ tepung tulang berdiameter $>500 \mu \mathrm{m}$ dosis $40 \mathrm{mg}$;

$\mathrm{T}_{13}=$ tepung tulang berdiameter $>500 \mu \mathrm{m}$ dosis $55 \mathrm{mg}$.

Data hasil pengamatan dianalisis dengan model sidik ragam (ANOVA) . Perbedaan antar perlakuan diuji dengan uji Duncan; perbedaan antara kontrol dan seluruh perlakuan dan antar ukuran diameter tepung tulang diuji dengan kontras ortogonal. Pengaruh dosis tepung tulang diuji dengan analisis regresi. Transformasi data dilakukan terhadap data yang tidak memenuhi asumsi kenormalan galat.

\section{HASIL DAN PEMBAHASAN}

\section{Pertumbuhan Tanaman}

Sumber $\mathrm{P}$ berpengaruh sangat nyata $(\mathrm{P}<0,01)$ terhadap pertumbuhan tanaman $P$. phaseoloides umur 12 MST. Tepung tulang pada dasarnya menghasilkan rataan bobot kering akar dan total tanaman $P$. phaseoloides yang sama dengan larutan pupuk buatan dan pengaruhnya ditentukan oleh ukuran diameter dan dosisnya (Tabel 1). Ukuran diameter tepung tulang $<250 \mu \mathrm{m}$ menghasilkan rataan bobot kering akar, pucuk, dan total tanaman $P$. phaseoloides yang tertinggi dan berbeda nyata, masingmasing sebesar 40,06; 160,49; dan 200,54 mg dibanding yang dihasilkan oleh tepung tulang berukuran diameter 250-500 $\mu \mathrm{m}$ dan $>500$. Terdapat hubungan linier terbalik dan kuadratik antara dosis tepung tulang dengan bobot kering akar, pucuk, dan total tanaman (Tabel 2). Hanya diperlukan tepung tulang sebanyak $10 \mathrm{mg}$ untuk menghasilkan bobot kering akar yang tinggi, namun untuk menghasilkan bobot kering pucuk dan total yang tinggi diperlukan dosis yang lebih tinggi, yaitu 37,6-38,3 mg.

Tabel 1. Rataan bobot kering tanaman P. phaseoloides umur 12 minggu setelah tanam (MST)

\begin{tabular}{|c|c|c|c|}
\hline \multirow{2}{*}{ Perlakuan } & \multicolumn{3}{|c|}{ Bobot kering (mg) } \\
\hline & Akar & Pucuk & Total \\
\hline $\mathrm{T}_{1}$ & $33,96 \pm 0,41^{\mathrm{fg}}$ & $136,89 \pm 1,96^{c}$ & $170,84 \pm 2,12^{\text {de }}$ \\
\hline $\mathrm{T}_{2}$ & $34,74 \pm 1,03^{\text {efg }}$ & $162,13 \pm 1,60^{\mathrm{b}}$ & $196,87 \pm 0,65^{\mathrm{b}}$ \\
\hline $\mathrm{T}_{3}$ & $44,50 \pm 1,80^{\mathrm{a}}$ & $171,67 \pm 2,19^{a}$ & $216,17 \pm 3,16^{a}$ \\
\hline $\mathrm{T}_{4}$ & $42,36 \pm 1,57^{\mathrm{ab}}$ & $173,95 \pm 1,46^{\mathrm{a}}$ & $216,31 \pm 3,02^{\mathrm{a}}$ \\
\hline $\mathrm{T}_{5}$ & $38,63 \pm 1,80^{\text {cd }}$ & $134,20 \pm 4,99^{\mathrm{cd}}$ & $172,83 \pm 4,19^{\mathrm{d}}$ \\
\hline $\mathrm{T}_{6}$ & $31,99 \pm 0,97^{\mathrm{gh}}$ & $115,97 \pm 1,85^{\mathrm{e}}$ & $147,96 \pm 1,32^{g}$ \\
\hline $\mathrm{T}_{7}$ & $35,80 \pm 0,24^{\text {def }}$ & $130,92 \pm 2,03^{\mathrm{d}}$ & $166,72 \pm 2,21^{\text {ef }}$ \\
\hline $\mathrm{T}_{8}$ & $40,11 \pm 1,53^{\mathrm{bc}}$ & $138,75 \pm 3,98^{c}$ & $178,85 \pm 3,14^{c}$ \\
\hline $\mathrm{T}_{9}$ & $37,28 \pm 0,75^{\text {cde }}$ & $134,07 \pm 1,81^{\mathrm{cd}}$ & $171,35 \pm 2,30^{\mathrm{de}}$ \\
\hline $\mathrm{T}_{10}$ & $26,01 \pm 3,45^{\mathrm{i}}$ & $76,95 \pm 2,18^{g}$ & $102,96 \pm 2,71^{\mathrm{i}}$ \\
\hline $\mathrm{T}_{11}$ & $29,36 \pm 2,99^{\mathrm{h}}$ & $106,70 \pm 2,80^{\mathrm{f}}$ & $136,06 \pm 3,53^{h}$ \\
\hline $\mathrm{T}_{12}$ & $35,87 \pm 0,57^{\text {def }}$ & $112,90 \pm 1,57^{\mathrm{e}}$ & $148,76 \pm 1,79 \mathrm{~g}$ \\
\hline $\mathrm{T}_{13}$ & $36,08 \pm 0,84^{\text {def }}$ & $129,41 \pm 3,65^{\mathrm{d}}$ & $165,49 \pm 4,22^{\mathrm{f}}$ \\
\hline Pupuk buatan $\left(\mathrm{T}_{1}\right)$ & $33,96 \pm 0,41^{\mathrm{A}}$ & $136,89 \pm 1,96^{\mathrm{A}}$ & $170,84 \pm 2,12^{\mathrm{A}}$ \\
\hline Tepung tulang $\left(\mathrm{T}_{2-13}\right)$ & $36,06 \pm 5,27^{\mathrm{A}}$ & $132,30 \pm 27,24^{\mathrm{B}}$ & $168,36 \pm 31,72^{\mathrm{A}}$ \\
\hline \multicolumn{4}{|l|}{ Diameter tepung tulang } \\
\hline$<250 \mu \mathrm{m}\left(\mathrm{T}_{2-5}\right)$ & $40,06 \pm 4,11^{\mathrm{A}}$ & $160,49 \pm 16,70^{\mathrm{A}}$ & $200,54 \pm 18,82^{\mathrm{A}}$ \\
\hline $250-500 \mu \mathrm{m}\left(\mathrm{T}_{6-9}\right)$ & $36,29 \pm 3,17^{B}$ & $129,93 \pm 9,17^{\mathrm{B}}$ & $166,22 \pm 12,07^{\mathrm{B}}$ \\
\hline$>500 \mu \mathrm{m}\left(\mathrm{T}_{10-13}\right)$ & $31,83 \pm 4,92^{\mathrm{C}}$ & $106,49 \pm 19,94^{C}$ & $138,32 \pm 24,10^{c}$ \\
\hline
\end{tabular}

Keterangan: Superskrip huruf kecil berbeda pada kolom yang sama menunjukkan berbeda nyata $(\mathrm{P}<0,05)$ dengan uji Duncan; superskrip huruf besar berbeda pada kolom yang sama menunjukkan berbeda nyata $(\mathrm{P}<0,05)$ dengan uji kontras ortogonal. 
Tabel 2. Persamaan regresi dosis tepung tulang terhadap bobot kering tanaman $P$. phaseoloides umur 12 minggu setelah tanam (MST)

\begin{tabular}{llcrc}
\hline Peubah tanaman & Persamaan regresi & Dosis optimal $(\mathrm{mg})$ & $\mathrm{R}^{2}$ & $\mathrm{P}$ \\
\hline Bobot kering akar & $\mathrm{y}=40,31-92,96 \mathrm{x}^{-1}$ & 10,0 & 0,90 & $<0,05$ \\
Bobot kering pucuk & $\mathrm{y}=98,31+2,30 \mathrm{x}-0,03 \mathrm{x}^{2}$ & 38,3 & 0,99 & $<0,05$ \\
Bobot kering total & $\mathrm{y}=122,89+3,01 \mathrm{x}-0,04 \mathrm{x}^{2}$ & 37,6 & 0,99 & $<0,05$ \\
\hline
\end{tabular}

Keterangan: $\mathrm{R}^{2}=$ koefisien determinasi, $\mathrm{P}=$ signifikansi

Kombinasi ukuran diameter dan dosis dengan demikian menentukan bobot kering tanaman $P$. phaseoloides. Tepung tulang ukuran diameter $<250 \mu \mathrm{m}$ dosis $25 \mathrm{mg}$ $\left(\mathrm{T}_{3}\right)$ dan $40 \mathrm{mg}\left(\mathrm{T}_{4}\right)$ menghasilkan rataan bobot kering akar, pucuk, dan total yang tidak berbeda nyata namun berbeda nyata dengan yang dihasilkan oleh perlakuan lainnya (Tabel 1).

\section{Kolonisasi dan Produksi Inokulum G. etunicatum}

Sumber fosfor (P) berpengaruh sangat nyata $(\mathrm{P}<0,01)$ terhadap kolonisasi $G$. etunicatum di akar $P$. phaseoloides umur 6 dan 12 MST. Tepung tulang menghasilkan kolonisasi mikoriza yang lebih rendah di akar P. phaseoloides umur 6 dan 12 MST dibandingkan pupuk buatan (Tabel 3). Namun demikian tepung tulang menghasilkan bobot kering akar terkolonisasi yang sama dan jumlah spora yang lebih tinggi dibandingkan pupuk buatan. Seperti halnya pengaruhnya terhadap bobot kering tanaman, tepung tulang dengan diameter $<250 \mu \mathrm{m}$ menghasilkan rataan kolonisasi akar, bobot kering akar terkolonisasi, dan jumlah spora yang lebih tinggi dibandingkan ukuran diameter yang lebih besar. Kolonisasi akar yang tinggi pada umur 6 MST dan 12 MST diperoleh jika tepung tulang diberikan dengan dosis yang tinggi, yaitu 46,0 dan 54,5 mg (Tabel 4). Tepung tulang berdiameter $<250 \mu \mathrm{m}$ dosis $25 \mathrm{mg}\left(\mathrm{T}_{3}\right)$ menghasilkan kolonisasi akar yang sama tingginya dengan yang dihasilkan pupuk buatan $\left(\mathrm{T}_{1}\right)$ pada umur 6 MST (Tabel 3). Kolonisasi akar yang rendah yang dihasilkan oleh perlakuan $\mathrm{T}_{4^{\prime}} \mathrm{T}_{5}, \mathrm{~T}_{7}, \mathrm{~T}_{8^{\prime}}, \mathrm{T}_{9^{\prime}} \mathrm{T}_{12}$ dan $\mathrm{T}_{13}$ pada umur 12 MST mampu menyamai kolonisasi pada umur 6 MST yang dihasilkan $\mathrm{T}_{1}$ dan $\mathrm{T}_{2}$. Kolonisasi akar yang rendah pada umur 6 MST dengan demikian juga dapat mening-

Tabel 3. Rataan kolonisasi akar dan jumlah spora mikoriza arbuskula dalam medium tumbuh P. phaseoloides umur 12 minggu setelah tanam (MST)

\begin{tabular}{|c|c|c|c|c|}
\hline \multirow{2}{*}{ Perlakuan } & \multicolumn{2}{|c|}{ Kolonisasi akar (\%) } & \multirow{2}{*}{$\begin{array}{c}\text { Bobot kering } \\
\text { akar terkolonisasi } \\
\text { (mg/tanaman) }\end{array}$} & \multirow{2}{*}{$\begin{array}{l}\text { Jumlah spora } \\
\text { (buah) }\end{array}$} \\
\hline & $6 \mathrm{MST}$ & $12 \mathrm{MST}$ & & \\
\hline $\mathrm{T}_{1}$ & $76 \pm 2^{\mathrm{a}}$ & $98 \pm 2^{a}$ & $33,76 \pm 0,32^{\mathrm{cd}}$ & $744 \pm 99^{\mathrm{e}}$ \\
\hline $\mathrm{T}_{2}$ & $65 \pm 1^{\mathrm{b}}$ & $80 \pm 6^{b}$ & $27,89 \pm 2,29^{\mathrm{e}}$ & $1.824 \pm 180^{\mathrm{abc}}$ \\
\hline $\mathrm{T}_{3}$ & $75 \pm 0^{a}$ & $99 \pm 2^{a}$ & $43,90 \pm 0,89^{a}$ & $2.368 \pm 219^{a}$ \\
\hline $\mathrm{T}_{4}$ & $68 \pm 3^{b}$ & $98 \pm 0^{a}$ & $41,51 \pm 1,53^{\mathrm{a}}$ & $2.173 \pm 491^{\mathrm{ab}}$ \\
\hline $\mathrm{T}_{5}$ & $60 \pm 1^{c}$ & $90 \pm 3^{\mathrm{ab}}$ & $34,77 \pm 0,59^{b}$ & $1.792 \pm 378^{\mathrm{abc}}$ \\
\hline $\mathrm{T}_{6}$ & $42 \pm 3^{g}$ & $60 \pm 8^{c}$ & $19,16 \pm 1,98^{f}$ & $1.320 \pm 78^{\mathrm{cd}}$ \\
\hline $\mathrm{T}_{7}$ & $49 \pm 4^{\mathrm{ef}}$ & $89 \pm 5^{a b}$ & $31,95 \pm 1,81^{\mathrm{de}}$ & $1.590 \pm 126^{\mathrm{abcd}}$ \\
\hline $\mathrm{T}_{8}$ & $55 \pm 5^{\mathrm{cd}}$ & $94 \pm 4^{\mathrm{ab}}$ & $37,57 \pm 2,90^{\mathrm{bc}}$ & $1.856 \pm 166^{\mathrm{abc}}$ \\
\hline $\mathrm{T}_{9}$ & $53 \pm 4^{\text {de }}$ & $98 \pm 0^{a}$ & $36,42 \pm 0,85^{\mathrm{d}}$ & $1.772 \pm 253^{\mathrm{abc}}$ \\
\hline $\mathrm{T}_{10}$ & $29 \pm 2^{\mathrm{i}}$ & $40 \pm 3^{\mathrm{d}}$ & $10,52 \pm 2,34^{\mathrm{h}}$ & $640 \pm 147^{\mathrm{e}}$ \\
\hline $\mathrm{T}_{11}$ & $35 \pm 2^{\mathrm{h}}$ & $54 \pm 17^{\mathrm{cd}}$ & $15,42 \pm 3,56^{g}$ & $1.187 \pm 109^{\mathrm{d}}$ \\
\hline $\mathrm{T}_{12}$ & $46 \pm 4^{\mathrm{fg}}$ & $83 \pm 15^{\mathrm{ab}}$ & $29,83 \pm 5,65^{\mathrm{e}}$ & $1.268 \pm 183^{\mathrm{cd}}$ \\
\hline $\mathrm{T}_{13}$ & $49 \pm 2^{\text {ef }}$ & $87 \pm 16^{\mathrm{ab}}$ & $31,16 \pm 5,28^{e}$ & $1.610 \pm 938^{\mathrm{abc}}$ \\
\hline Pupuk buatan $\left(\mathrm{T}_{1}\right)$ & $76 \pm 2^{\mathrm{A}}$ & $98 \pm 2^{\mathrm{A}}$ & $33,36 \pm 0,32^{\mathrm{A}}$ & $744 \pm 99^{\mathrm{B}}$ \\
\hline Tepung tulang $\left(\mathrm{T}_{2-13}\right)$ & $52 \pm 13^{\mathrm{B}}$ & $81 \pm 20^{\text {в }}$ & $30,01 \pm 10,29^{\mathrm{A}}$ & $1.616 \pm 539^{\mathrm{A}}$ \\
\hline \multicolumn{5}{|c|}{ Diameter tepung tulang } \\
\hline$<250 \mu \mathrm{m}$ & $67 \pm 6^{\mathrm{A}}$ & $92 \pm 8^{\mathrm{A}}$ & $37,01 \pm 6,64^{\mathrm{A}}$ & $2.039 \pm 385^{\mathrm{A}}$ \\
\hline $250-500 \mu \mathrm{m}$ & $50 \pm 6^{\mathrm{B}}$ & $85 \pm 16^{\mathrm{A}}$ & $31,28 \pm 7,82^{\mathrm{B}}$ & $1.635 \pm 258^{\text {B }}$ \\
\hline$>500 \mu \mathrm{m}$ & $39 \pm 9 \mathrm{C}$ & $66 \pm 24^{\mathrm{B}}$ & $21,74 \pm 10,07 \mathrm{C}$ & $1.176 \pm 551^{\mathrm{C}}$ \\
\hline
\end{tabular}

Keterangan: Superskrip huruf kecil berbeda pada kolom yang sama menunjukkan berbeda nyata $(P<0,05)$ dengan uji Duncan; superskrip huruf besar berbeda pada kolom yang sama menunjukkan berbeda nyata $(\mathrm{P}<0,05)$ dengan uji kontras ortogonal. 
Tabel 4. Persamaan regresi dosis tepung tulang terhadap kolonisasi akar umur 6 minggu setelah tanam (MST), kolonisasi dan bobot kering akar terkolonisasi dan jumlah spora umur 12 MST tanaman $P$. phaseoloides

\begin{tabular}{llccc}
\hline Peubah tanaman & \multicolumn{1}{c}{ Persamaan regresi } & Dosis optimal $(\mathrm{mg})$ & $\mathrm{R}^{2}$ & $\mathrm{P}$ \\
\hline Kolonisasi akar 6 MST & $\mathrm{y}=37,21+0,92 \mathrm{x}-0,01 \mathrm{x}^{2}$ & 46,0 & 0,99 & $<0,05$ \\
Kolonisasi akar 12 MST & $\mathrm{y}=40,54+2,18 \mathrm{x}-0,02 \mathrm{x}^{2}$ & 54,5 & 0,99 & $<0,05$ \\
Bobot kering akar terkolonisasi & $\mathrm{y}=40,31-92,96 \mathrm{x}^{-1}$ & 10,0 & 0,90 & $<0,05$ \\
Jumlah spora & $\mathrm{y}=1.901,23-6.214,68 \mathrm{x}^{-1}$ & 10,0 & 0,95 & $<0,05$ \\
\hline
\end{tabular}

Keterangan: $\mathrm{R}^{2}=$ koefisien determinasi, $\mathrm{P}=$ signifikansi

kat sampai maksimal jika umur tanaman bertambah. Kolonisasi akar yang tinggi tidak selalu menghasilkan bobot kering akar terkolonisasi yang tinggi pula. Bobot kering akar terkolonisasi yang tinggi dan berbeda nyata dengan yang lainnya hanya dihasilkan oleh tepung tulang diameter $<250 \mu \mathrm{m}$ dosis $25 \mathrm{mg}\left(\mathrm{T}_{3}\right)$ dan dosis $40 \mathrm{mg}$ ( $\left.\mathrm{T}_{4}\right)$ (Tabel 3).

Pengaruh dosis tepung tulang terhadap jumlah spora ditentukan oleh ukuran diameternya. Dosis tepung tulang tidak mempengaruhi jumlah spora jika diberikan dengan ukuran diameter $<250 \mu \mathrm{m}$ dan 250-500 $\mu \mathrm{m}$ namun diperlukan dosis yang lebih besar jika diberikan dengan ukuran diameter $>500 \mu \mathrm{m}$ (Tabel 3). Hanya diperlukan tepung tulang sebesar $10 \mathrm{mg}$ untuk mendapatkan jumlah spora yang tinggi (Tabel 4).

Hasil penelitian ini menunjukkan bahwa tepung tulang sapi memiliki potensi sebagai sumber hara yang sama baiknya dibandingkan pupuk buatan untuk meningkatkan pertumbuhan tanaman $P$. phaseoloides dan bahkan lebih unggul jika digunakan untuk memproduksi spora FMA G. etunicatum. Ragam pengaruh yang dihasilkan kedua jenis pupuk tersebut disebabkan perbedaan kadar hara dan sifat kelarutan pupuk. Pupuk buatan mengandung unsur P (1,09\%) yang jauh lebih rendah dan unsur $N$ yang jauh lebih tinggi (25\%) dibandingkan dengan tepung tulang sapi, namun tepung tulang sapi mengandung unsur mikro yang lebih lengkap. Setiap unsur hara dilaporkan menghasilkan pengaruh spesifik terhadap perkembangan simbiosis FMA. Unsur $\mathrm{N}$, khususnya dalam bentuk $\mathrm{NO}_{3}{ }_{3}$, dilaporkan meningkatkan jumlah runner hifa, percabangan hifa untuk penyerapan hara, dan jumlah spora sedangkan unsur P menyebabkan hifa ekstraradikal berkembang ke arah radial (Bago et al., 2004). Tepung tulang mengandung unsur Ca yang tinggi dan dapat meningkatkan kekakuan dinding sel akar (Havlin et al., 2005) sehingga dapat memperlambat kolonisasi akar. Tepung tulang juga mengandung sejumlah unsur mikro yang tidak dikandung oleh pupuk buatan.

Pupuk buatan memiliki kelarutan yang tinggi sehingga mampu menyediakan lebih banyak unsur $P$ pada tahap awal pertumbuhan namun secara berangsur akan berkurang karena bereaksi dengan partikel penyusun medium tumbuh atau diserap oleh tanaman dan jasad renik rhizosfir (Havlin et al., 2005). Sebaliknya, pelepasan $\mathrm{P}$ dari tepung tulang berlangsung secara bertahap disesuaikan dengan umur dan kebutuhan tanaman. Tepung tulang pada umumnya memiliki kelarutan yang tergolong sedang, jadi terletak di antara TSP (berpelepasan cepat) dan batuan fosfat (berpelepasan lambat), dan kelarutannya ditentukan oleh kadar air medium tumbuh (Warren et al., 2009). Sebagian besar P dari tepung tulang berbentuk $\mathrm{P}$ larut asam dan hanya sebagian kecil yang larut air (Ylivainio et al., 2008). Oleh karena itu kemasaman rhizosfir, yang umumnya semakin meningkat seiring dengan umur tanaman, berpengaruh besar terhadap pelarutan P dari tepung tulang. Pelarutan P dari tepung tulang pada umumnya terjadi pada 20 hari pertama (Warren et al., 2009). Pemasaman rhizosfir, misalnya melalui eksudasi asam organik, dan simbiosis FMA merupakan salah satu strategi tanaman mendapatkan berbagai bentuk $\mathrm{P}$ dari dalam medium tumbuh (Lynch \& Brown, 2008). Perkecambahan spora G. etunicatum telah dilaporkan tidak dipengaruhi oleh kadar P tinggi dan sporulasinya berkorelasi positif dengan kadar hara P (Carrenho et al., 2001). Kadar P total tepung tulang sapi yang lebih tinggi dibandingkan dengan pupuk buatan komersial tidak berdampak negatif terhadap pembentukan dan perkembangan simbiosis MA karena unsur P dilepaskan secara bertahap sesuai dengan umur dan kebutuhan tanaman. Berbagai bentuk P sulit larut seperti batuan fosfat, kalsium fosfat dan tepung tulang, telah dilaporkan efektif untuk memelihara FMA dan meningkatkan pertumbuhan tanaman dalam jangka panjang (Nikolaou et al., 2002).

Faktor ukuran tepung tulang, selain kadar hara dan dosis yang digunakan, juga mempengaruhi respon tanaman dan pembentukan simbiosis MA. Semakin kecil ukuran sebuah benda semakin besar luas permukaannya. Luas permukaan yang semakin besar menjamin proses pertukaran atau pelepasan hara yang semakin intensif sebagaimana terjadi pada partikel lempung (clay) (Havlin et al., 2005). Ukuran diameter tepung tulang giling yang lebih kecil mampu menyediakan hara dalam tempo yang lebih singkat dibandingkan yang berukuran lebih besar sehingga menghasilkan pengaruh yang lebih baik terhadap pertumbuhan tanaman dan simbiosis MA. Namun demikian pengaruh positif ukuran diameter tepung tulang dibatasi oleh dosisnya. Semakin tinggi dosis tepung tulang berarti semakin banyak hara yang dapat disediakan. Karena tepung tulang mengandung $\mathrm{P}$ yang lebih tinggi dibandingkan dengan pupuk buatan, maka pengaruh tepung tulang menjadi menurun jika diberikan dengan bobot yang semakin meningkat. Tepung tulang berukuran $<250 \mu \mathrm{m}$ menghasilkan pengaruh yang positif untuk perkembangan simbiosis G. etunicatum dan pertumbuhan tanaman $P$. phaseoloides sampai pada batas dosis $25-40 \mathrm{mg}$. Tepung tulang giling berukuran $>250$ 
Tabel 5. Regresi antara peubah tanaman dengan jumlah spora per $100 \mathrm{~g}$ inokulan

\begin{tabular}{llcc}
\hline \multicolumn{1}{c}{ Peubah tanaman } & Persamaan regresi & $\mathrm{R}^{2}$ & $\mathrm{p}$ \\
\hline Bobot kering akar & $\mathrm{y}=-772+29.208 \mathrm{x}^{-1}$ & 0,50 & $<0,01$ \\
Bobot kering pucuk & $\mathrm{y}=-548+76.176 \mathrm{x}^{-1}$ & 0,66 & $<0,01$ \\
Bobot kering total & $\mathrm{y}=-602+10.6361 \mathrm{x}^{-1}$ & 0,64 & $<0,01$ \\
Kolonisasi akar 6 MST & $\mathrm{y}=-399+22.116 \mathrm{x}^{-1}$ & 0,54 & $<0,01$ \\
Kolonisasi akar 12 MST & $\mathrm{y}=-382+32.828 \mathrm{x}^{-1}$ & 0,65 & $<0,01$ \\
Bobot kering akar terkolonisasi & $\mathrm{y}=-224+7.075 \mathrm{x}^{-1}$ & 0,67 & $<0,01$ \\
\hline
\end{tabular}

Keterangan: $\mathrm{R}^{2}=$ koefisien determinasi; $\mathrm{P}=$ signifikansi; $\mathrm{MST}=$ minggu setelah tanam .

um harus diberikan dengan bobot yang lebih tinggi agar menghasilkan pengaruh yang sama baiknya dengan yang berukuran $<250 \mu \mathrm{m}$.

Penyediaan hara yang lebih baik telah diketahui menjamin lebih baiknya pertumbuhan tanaman inang dan pembentukan struktur FMA intra- (hifa intraradikal, vesikel, dan arbuskula) dan ekstraradikal (hifa ekstraradikal dan spora) (Olsson et al., 2010). Lebih baiknya pertumbuhan tanaman inang menjamin kecukupan karbon yang ditranslokasikan ke akar untuk pembentukan struktur FMA intra- dan ekstraradikal. Sekitar $20 \%$ karbon hasil fotosintesis dialokasikan ke tanaman inang untuk pembentukan struktur FMA (Smith \& Read, 2008). Translokasi karbon ke akar diwujudkan dalam bentuk peningkatan pembentukan biomassa akar sehingga meningkatkan permukaan yang dapat dikolonisasi oleh FMA.

Spora FMA terbentuk dari ujung hifa ekstraradikal yang menggelembung dan kemudian terlepas (Smith \& Read, 2008). Hifa ekstraradikal terbentuk dari hifa intraradikal yang menjulur keluar dari akar dan membentuk percabangan yang ekstensif di rhizosfir tanaman. Semakin banyak hifa ekstraradikal dengan demikian berpotensi meningkatkan pembentukan spora bergantung kepada jenis FMA dan faktor luar seperti pasokan karbon dan ketersediaan hara. Semakin banyak hifa ekstraradikal dan spora yang terbentuk bermakna semakin banyak karbon yang harus diekskresikan rhizosfir yang dapat menurunkan biomassa tanaman inang. Kolonisasi akar juga tidak selalu berkorelasi positif dengan jumlah spora karena dihitung berdasarkan kenampakan struktur FMA dalam akar. Hal tersebut terbukti dari adanya hubungan linier negatif antara bobot kering tanaman dan kolonisasi akar dengan jumlah spora yang terbentuk (Tabel 5). Korelasi negatif antara pertumbuhan tanaman inang dan kolonisasi akar dengan jumlah spora FMA telah dilaporkan sebelumnya oleh para peneliti (Aliasgharzadeh et al., 2001; Isobe et al., 2008).

Jumlah spora G. etunicatum yang dihasilkan pada penelitian ini jauh lebih tinggi dibandingkan dengan jumlah spora yang dihasilkan oleh peneliti lain. Chalimah et al. (2007) menggunakan tanaman $P$. phaseoloides yang dipasok dengan pupuk buatan yang sama dengan penelitian ini tapi dosisnya 2x lipat hanya mampu menghasilkan 35 buah spora Gigaspora margarita dan 49 buah spora Acaulospora tuberculata pada umur 12 MST. Nurbaity et al. (2009) menggunakan media arang sekam dan zeolit, sorghum sebagai inang, dan mycofer (campuran Glomus manihotis, G., Acaulospora dan $G$. etunicatum) ternyata hanya mampu menghasilkan 20-25 spora pada umur 70 HST. Karakter G. etunicatum yang mampu menggandakan diri dengan cepat jika ditumbuhkan dalam pot (Troeh \& Loynachan, 2009) dan karakter sumber hara yang digunakan pada percobaan ini dapat menjadi penyebab perbedaan hasil penelitian ini.

Ukuran butir tepung tulang yang lebih kecil menghasilkan dampak positif yang lebih cepat terhadap pertumbuhan tanaman dan simbiosis MA. Namun demikian untuk mendapatkan tepung tulang berukuran yang lebih kecil memerlukan penyaringan yang selain memerlukan tenaga kerja dan waktu juga meningkatkan proporsi bahan yang terbuang atau tidak dipakai. Selain itu, ukuran tepung tulang yang semakin kecil juga meningkatkan proporsi tepung tulang yang tercuci dalam periode produksi inokulum menggunakan kultur pot. Ukuran yang halus juga berpotensi meningkatkan volume air yang ditahan sehingga dapat memperlambat sporulasi. Kesemua hal tersebut berdampak kepada semakin tingginya biaya produksi inokulan.

Ukuran yang lebih besar menjadikan lebih sedikitnya bahan yang hilang akibat tidak terpakai atau tercuci selama produksi inokulan FMA. Pelepasan hara dari tepung tulang yang berukuran lebih besar juga berlangsung lebih lambat karena luas permukaannya yang kecil sehingga dalam jangka panjang lebih menguntungkan, khususnya untuk memproduksi FMA yang sporulasinya lambat misalnya Acaulospora. Ukuran yang lebih besar, yang bermakna tidak perlu ada alokasi tenaga kerja dan waktu untuk penyaringan. Penggunaan tepung tulang berukuran besar dengan demikian dalam jangka panjang lebih menguntungkan untuk digunakan dalam proses produksi inokulan FMA maupun untuk meningkatkan pertumbuhan legum pakan ternak.

\section{KESIMPULAN}

Tepung tulang giling merupakan sumber hara yang sama baiknya dengan pupuk buatan untuk meningkatkan bobot kering total tanaman dan kolonisasi fungi mikoriza arbuskula (FMA) pada akar tanaman $P$. Phaseoloides, namun merupakan sumber hara yang lebih baik untuk memproduksi spora FMA G. etunicatum. Tepung tulang giling berukuran halus $(<250 \mu \mathrm{m})$ dengan bobot $25 \mathrm{mg}$ diperlukan untuk meningkatkan pertumbuhan atau bobot kering tanaman pakan ternak $P$. 
phaseoloides. Tepung tulang giling dengan ukuran halus $(<250 \mu \mathrm{m})$ maksimal sebanyak $40 \mathrm{mg}$ atau berukuran kasar $(>250 \mu \mathrm{m})$ namun dengan bobot yang lebih tinggi (>40 mg) dapat diaplikasikan untuk memproduksi inokulan FMA G. etunicatum .

\section{UCAPAN TERIMA KASIH}

Ucapan terima kasih disampaikan kepada Direktorat Jenderal Pendidikan Tinggi Kementerian Pendidikan Nasional Republik Indonesia yang telah memberikan beasiswa BPPS kepada penulis pertama untuk mengikuti program S3 pada Sekolah Pascasarjana Institut Pertanian Bogor.

\section{DAFTAR PUSTAKA}

Aliasgharzadeh, N., N. S. Rastin, H. Towfighi, \& A. Alizadeh. 2001. Occurrence of arbuscular mycorrhizal fungi in saline soils of the Tabriz Plain of Iran in relation to some physical and chemical properties of soil. Mycorrhiza 11:119-122.

Bago, B., C. Cano, C. Azcon-Aguilar, J. Samson, A. P. Coughlan, \& Y. Piche. 2004. Differential morphogenesis of the extraradical mycelium of an arbuscular mycorrhizal fungus grown monoxenically on spatially heterogeneous culture medium. Mycologia 96:452-462.

Biofertilizer Project Group. 2006. Biofertilizer Manual. Forum for Nuclear Cooperation in Asia, Japan Atomic Industrial Forum, Tokyo.

Carrenho, R., E. S. Silva, S. F. B. Trufem, \& V. L. R. Bononi. 2001. Succesive cultivation of maize and agricultural practices on root colonization, number of spores and species of AM fungi. Braz. J. Microbiol. 32:262-270.

Chalimah, S., Muhadiono, L. Aznam, S. Haran, \& N. ToruanMathius. 2007. Perbanyakan Gigaspora sp dan Acaulospora sp dengan kultur pot di rumah kaca. Biodiversitas 7:12-19.

Feldmann F., I. Hutter, \& C. Schneider. 2009. Best production practice of arbuscular mycorrhizal inoculum. Soil Biol. 18:319-335

Havlin, J. L., J. D. Beaton, S. L. Tisdale, \& W. L. Nelson. 2005. Soil Fertility and Fertilizers. An Introduction to Nutrient Management. Prentice Hall, New Jersey.

Isobe, K., H. Sugimura, T. Maeshima, \& R. Ishii. 2008. Distribution of arbuscular mycorrhizal fungi in upland field soil of Japan - 2. Spore density of arbuscular mycorrhizal fungi and infection ratio in soybean and maize fields. Plant Prod. Sci. 11:171-177.
Karti, P. D. M. H. 2004. Pengaruh pemberian cendawan mikoriza arbuskula terhadap pertumbuhan dan produksi rumput Setaria splendida Stapf yang mengalami cekaman kekeringan. Med. Pet. 27: 63-68

Lukiwati, D. R. 2007. Dry matter production and digestibility Improvement of Centrosema pubescens and Pueraria phaseoloides with rock phosphate fertilization and VAM inoculation. Jurnal Ilmu-Ilmu Pertanian Indonesia 9: 1-5

Lynch, J. P. \& K.M. Brown. 2008. Root strategies for phosphorus acquisition. In: P. J. White \& J. P. Hammond (Eds). The Ecophysiology of Plant-Phosphorus Interactions. Springer Verlag. Heildelberg. p. 83-115.

Nikolaou, N., N. Karagiannidis, S. Koundouras, \& I. Fysarakis. 2002. Effects of different P sources in soil on increasing growth and mineral uptake of mycorrhizal Vitis vinifera L. (cv Victoria) vines. J. Int. Sci. Vigne. Vin 36:195-204.

Nurbaity, A., D. Herdiyantoro, \& O. Mulyani. 2009. Pemanfaatan bahan organik sebagai bahan pembawa Inokulan fungi mikoriza arbuskula. J. Biol. XIII:17-11.

Nusantara, A. D., I. Mansur, C. Kusmana, L. K. Darusman, \& Soedarmadi. 2007. Peran substrat alami, kadar air, dan sterilisasi dalam produksi spora melalui simbiosis Pueraria javanica dan Glomus etunicatum. Jurnal Akta Agrosia Edisi Khusus No. 2:204-212

Olsson, P. A., J. Rahm, \& N. Aliasgharzadeh. 2010. Carbon dynamics in mycorrhizal symbioses is linked to carbon costs and phosphorus benefits. FEMS Microbiol. Ecol. 72: 123-131

Romer, W. 2006. Plant availability of P from recycling products and phosphate fertilizers in a growth-chamber trial with rye seedlings. J. Plant Nutr. Soil Sci. 169:826-832.

Siviero, M. A., A. M. Motta, D. D. S. Lima, R. R. Birolli, S. Y. Huh, I. A. Santinoni, L. S. Murate, C. M. A. de Castro, M. Y. H. Miyauchi, W. Zangaro, M. A. Nogueira, \& G. Andrade. 2008. Interaction among N-fixing bacteria and AM fungi in Amazonian legume tree (Schizolobium amazonicum) in field conditions. Appl. Soil Ecol. 39:144-152.

Smith, S. E. \& D. J. Read. 2008. Mycorrhizal Symbiosis. $3^{\text {rd }}$ ed. Academic Press, San Diego.

Troeh, Z. I. \& T. E. Loynachan. 2009. Diversity of arbuscular mycorrhizal fungal species in soils of cultivated soybean fields. Agron. J. 101:1453-1462

Warren, G. P., J. S. Robinson, \& E. Someus. 2009. Dissolution of phosphorus from animal bone char in 12 soils. Nutr. Cycl. Agroecosyst. 84:167-178.

Ylivainio, K., R. Uusitalo, \& E. Turtola. 2008. Meat bone meal and fox manure as $\mathrm{P}$ sources for ryegrass (Lolium multiflorum) grown on a limed soil. Nutr. Cycl. Agroecosyst. $81: 267-278$ 